\title{
Fieldwork practice for learning: Lessons from occupational therapy students and their supervisors
}

\author{
D Naidoo, ${ }^{1}$ MOT; J van Wyk, ${ }^{2} \mathrm{PhD}$ Education \\ ${ }^{1}$ Discipline of Occupational Therapy, School of Health Sciences, University of KwaZulu-Natal, Durban, South Africa \\ ${ }^{2}$ Clinical and Professional Education, Nelson R Mandela School of Medicine, School of Clinical Medicine, University of KwaZulu-Natal, Durban, South Africa
}

Corresponding author: D Naidoo (naidoodes@ukzn.ac.za)

Background. Fieldwork practice forms a vital part of occupational therapy (OT) education and contributes significantly to competent practice and students' clinical reasoning. Students' learning is positively or negatively influenced by their fieldwork experience.

Objective. To explore the views and experiences of final-year OT students, site-based clinicians and university-based academic supervisors to identify strategies that influenced students' learning during fieldwork practice.

Methods. This descriptive qualitative study used a purposeful sampling technique. Data collection strategies included focus group discussions with clinical and academic supervisors and semistructured interviews with final-year students. Each set of data was analysed according to the research questions. The researcher analysed the data into themes, which were corroborated by a supervisor. Data source and analyst triangulation ensured trustworthiness of the study.

Results. Two themes, i.e. difficulties experienced by students during fieldwork and supervision strategies that they found beneficial for learning, are described. Guidance and mentoring from experienced therapists helped students to link observations from assessments and intervention plans. Observations of treatment sessions, peer learning and practice in the skills laboratories were beneficial for learning, competence and confidence. Guided questions from supervisors to enhance reflexive practice and peer learning strengthened the students' confidence and ability to give feedback to their peers. The students also benefited from sessions that allowed them the freedom and space to work autonomously.

Conclusion. This study provides insight into the difficulties that students experienced when engaging with fieldwork and offers some strategies that have been found to advance their learning.

Afr J Health Professions Educ 2016;8(1):37-40. DOI:10.7196/AJHPE.2016.v8i1.536

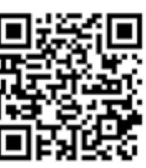

Students who enrol in occupational therapy (OT) at the University of KwaZulu-Natal (UKZN), Durban, South Africa (SA) follow a 4-year degree programme, which includes theoretical and practical components.

Fieldwork placement constitutes the main practical component of the undergraduate training programme ${ }^{[1]}$ and involves rotation of students in groups of 2 - 4 through four 6-week placements at government hospitals or non-governmental organisations (NGOs).

Fieldwork placement allows students opportunities for learning by integrating their theory into practice, conceptualising what professionalism entails and providing a chance to practise their professional skills in a supportive environment. Furthermore, it affords them the opportunity to engage with members of communities through service delivery ${ }^{[2]}$ They can also gain knowledge about their profession while learning how to practise as health professionals. In this way they learn to identify the strengths and shortfalls of their interventions, while developing a repertoire of professional practice and clinical reasoning skills. ${ }^{[2]}$

Learning during fieldwork encompasses a multimodal and complex experience where students become engaged in socially authentic workplace experiences in environments that shape their learning. ${ }^{[3]}$ Generally, on commencing fieldwork practice, they enter a complex and relatively unknown world, with differing social and cultural realities. There is therefore a need not only to prepare students for the variety of contexts where they will work, but also to ensure that they can benefit from the quality of the fieldwork exposures. The latter may include becoming familiar with the disintegrating social systems in primary healthcare settings; exposure to crime; and abuse, poverty and the realities and limitations of resources in their local areas. ${ }^{[4]}$ The transition from student to practitioner requires that the theories and techniques initially acquired in the classroom context be transferred to the clinical context. Furthermore, planning and implementing a comprehensive contextualised client treatment programme entails clinical reasoning and decision-making skills. A lack of adequate preparation may render the students' therapy ineffective.

With the entry-level OT practitioners' learning firmly embedded in their ability to practise effectively in the community, the quest remains for academic institutions to ensure that students make a successful transition to the role of a novice practitioner, notwithstanding the challenging circumstances. In recognising the value of fieldwork for learning, the Health Professions Council of South Africa (HPCSA) has mandated that a minimum of 1000 fieldwork hours be completed by OT students before their graduation. ${ }^{[1]}$ The need to reach consensus on the concept of professional behaviour and for clinicians to guide students to attain the required competencies has been highlighted. ${ }^{[5]}$ Clinical supervisors' personal beliefs and prior experiences have been found to influence their assessment of students' performance. ${ }^{[5]}$ The need for training to improve the validity of student performance assessments is noted by Snyman ${ }^{[6]}$ Incongruence in rating students' clinical performance is exacerbated in the absence of collaboration between site-based clinical supervisors and university academics. There is therefore a need for academic institutions to review the implementation of fieldwork practice, guidance and assessment of students during this important practical work-based experience.

In the Discipline of Occupational Therapy at UKZN, final-year students rotate in groups of 2 - 4 through four 6-week fieldwork placements in their final year, forming the bulk of the 1000 hours of clinical practice required for graduation. The sites for the fieldwork include placements at district or tertiary-level hospitals, NGOs and one peri-urban site. Given the severe staff shortages at a number of placement sites, some students may be expected to perform the duties of a qualified OT while being supervised by the only remaining OT at the hospital. The students are supervised primarily by the $\mathrm{OT}$ at the site; however, they receive additional supervision from an allocated academic supervisor once a week. This highlights the need for efficient 
supervision strategies to facilitate the student's acquisition of professional behaviour and learning of practice skills.

One of the key challenges for supervisors is fostering and developing professional behaviour of students, ${ }^{[6]}$ which entails introducing new theoretical ideas and knowledge as a necessary foundation for practice. It also comprises experimenting with and evaluating the success of interventions in the practical and clinical context. ${ }^{[7]}$ While authors agree that ethics, cultural competence, empathy and therapeutic use of self are important aspects of professional behaviour, limited literature exists to describe how these attributes can be taught to students. A considerable amount of literature has acknowledged the impact and difficulty brought about by the rapid expansion of tertiary education and the increased diversity of students because of broadened access and redress policies in the SA setting. The changes in students' preparedness for tertiary training and characteristics of millennial students who seek training have implications for the skills of supervisors and effectiveness of instructional methods for training, including fieldwork. ${ }^{[8]}$

In the absence of theories to explain how OT students negotiate fieldwork and supervision strategies that best assist their learning, this article reports on a study that explored the opinions of final-year OT students and their academic and clinical supervisors on the difficulties that students encounter during their fieldwork experience and the supervision strategies that they found beneficial during their various placements.

\section{Methods}

A descriptive qualitative study was used to gain an understanding of the perceptions and concerns of final-year OT students and their academic and clinical supervisors with regard to their fieldwork experience at an SA institution of higher learning. ${ }^{[9]}$ Purposeful sampling was used to identify potential participants. All final-year students $(N=21)$ who had studied at UKZN for the full duration of their degree, clinical supervisors $(N=7)$ and academic supervisors $(N=5)$ who supervised for $\geq 2$ years were invited via email to participate in the study. All potential participants were sent information documents and the informed consent letter with a request to volunteer.

Seventeen final-year students who were in the final semester of their undergraduate programme, 7 of their clinical supervisors and 5 academic supervisors agreed to share their views and experiences about fieldwork. The student sample consisted mainly of females $(n=16)$ aged between 21 and 27 years, from all racial groups. The supervisors in the sample were aged from 25 to 59 years, with clinical supervisory experience from 2 to 36 years. The supervisors were white and Indian and only one was a male.

There were three data sources, i.e. the students, supervisors and data gained from the curriculum documents. Two focus groups $(n=13)$ and four semistructured interviews were conducted with students by two practising experienced OTs who were trained as research assistants. (The schedule of questions is given in Appendix A.) This allowed for student anonymity and provided greater reliability by reducing potential research bias, as the principal investigator was a member of the academic staff in the Discipline of Occupational Therapy at UKZN, which could have impacted on the veracity and integrity of the feedback. Two focus groups were facilitated by the principal investigator to collect data from the clinical supervisors and the academic supervisors, respectively. The focus group sessions and the interviews were audiorecorded and transcribed.

Each set of data was analysed in answer to the research question. The researcher analysed the data into themes; these were corroborated by a supervisor. Triangulation of data collection methods (focus groups, semistructured interviews) and the use of two data analysts enhanced the trustworthiness of the research process and the generated data. Informed consent, voluntary withdrawal and potential bias were reduced by an experienced research assistant who is a qualified OT practitioner. Ethical clearance was obtained from the UKZN's Health and Social Sciences Ethics Committee (HSS/0761/012M).

\section{Results}

The two themes outlined in this article relate to the difficulties experienced by students during fieldwork, and to the supervision strategies that were identified as beneficial for learning. Subthemes are further reported within each respective theme.

\section{Difficulties experienced by students during fieldwork}

The difficulties that students encountered during fieldwork practice include anxiety about failing because they are mark driven, a need for clear guidelines, difficulty with clinical reasoning and a lack of understanding of the diverse contexts of their patients.

\section{Mark driven and anxious about failing}

Both the clinical site-based and academic supervisors identified the students' desire to obtain high marks and its impact on their motivation to learn. They noted how a desire to score well inspired the students and how fear of failure increased anxiety. The supervisors also noted that students employed very limited initiative and self-directed learning, which increased their dependence on the supervisors.

'They lack confidence in approaching their supervisor to ask for help and to discuss things ..., they expect the supervisor to organise their day and structure supervision times for them which can help?' (Clinical supervisor focus group, Participant 6)

'I think the initiative to go and find out more is lacking ... they need to be told what to do.' (Academic supervisors, Participant A)

\section{Need for clear guidelines}

The students and clinical supervisors reported a need for clear guidelines or expectations to ensure a successful fieldwork experience. One student discussed it in the following way:

'They must also like, ... tell me from the very beginning what they want ... and okay, ... such as you not doing the right thing and you gonna fail and all ... . So that it gives me a chance to improve.' (Student focus group, Participant 3)

'Set expectations so student know what you want ... so they come into their prac sessions more prepared on a daily basis.' (Clinical supervisor focus group, Participant 2)

\section{Difficulty with clinical reasoning}

The clinical and academic supervisors reported that students had difficulty linking their observation of a patient to their assessment. Moreover, students experienced difficulty when constructing a patient problem list and linking it to appropriate intervention strategies. Students requested generic steps (recipes) relating to therapies and experienced difficulty in planning alternative sessions. They also lacked the skills needed to adapt sessions and failed to demonstrate adequate problem-solving during sessions.

'They can't interpret it [assessment] and ... their observation skills are lacking.' (Academic supervisor focus group, Participant D)

'There's no link between the assessment to the problem list to the treatment, you don't see that follow through'. (Clinical supervisor focus group, Participant 4) 
'Want to do the treatment based on ... the basic recipes that they've been taught ... so lack of focus of it, difficulty to see that what's working, what's not.' (Academic supervisor focus group, Participant B)

'They struggle with the grading and adapting, they're afraid to change the activity if it's not working at that point because they plan this and they gonna stick to that. And they don't have back up plans.' (Clinical supervisor focus group, Participant 3)

\section{Lack of understanding of the diverse contexts of their patients}

Students' lack of understanding of the diverse contexts of their patients' lived experiences impacted on their ability to provide effective therapy.

'Most of our students are middle-classed, they don't have to take the bus and the taxi ... how do we then expect them to then problem solve for our clients who live in those circumstance.' (Academic supervisor focus group, Participant D)

'They actually have no idea of the context which the client is ... is going back to so it becomes a programme that's really not of benefit to the client.' (Clinical supervisor focus group, Participant 2)

\section{Supervision strategies found beneficial}

All participants found guidance and mentoring beneficial for understanding links between observations from assessments and patients' intervention plans. Furthermore, the use of active teaching strategies, such as reflective journals, peer learning and the skills laboratory, enhanced learning. Allowing students freedom and autonomy with intervention sessions and ensuring that there was constructive feedback was the final subtheme.

\section{Guidance and mentoring}

Clinical and academic supervisors found that verbalising and explaining their clinical reasoning process with regard to the problem list was a useful intervention, which seemingly improved students' professional skills.

'Explaining what's going on in my mind out loud, I feel that they then latch onto that and they will engage in conversation, will learn from it. (Academic supervisor focus group, Participant A)

'Sit with them ... drawing up a problem list ... they can start seeing where things [patients problem areas] were clustering and plan intervention from there.' (Academic supervisor focus group, Participant C)

'The supervision and the guidance from a supervisor, it's really helpful cause it also makes you feel ... umm ... you going somewhere, like you actually doing something right.' (Student focus group, Participant 8)

\section{Active teaching strategies}

The use of reflective journals with prompts in the form of questions allowed students to reflect on their clinical reasoning and actions during the fieldwork session. This included observations of the scope of the therapist's treatment plan, the impact of peer learning on their understanding and skills, and the use of skills laboratories to practise skills in a safe environment.

'Practical sessions, demonstration, watching ... watching an experienced therapist handle a situation. Uhm, we're not confident in the way we do it and we need to know that someone else does it that kind of way.' (Students focus group, Participant 6)
'I also found that getting them to sit in on each other's sessions have helped them inside building for their own activity ... umm ... also giving positive or negative feedback to their colleague or their friends.' (Clinical supervisor focus group, Participant 3)

Students' freedom and autonomy, and providing constructive feedback Students further benefited from flexible planning during sessions and freedom and space to work autonomously. Supervisors found that encouraging students to be flexible in their sessions helped to build their confidence to cope with problems arising in the session. Constructive feedback and evaluation of sessions with students were valued.

'What I've asked my students to do is to do their plan session and then do something that they haven't tried before ... so just try another activity, see how it would work.' (Clinical supervisor focus group, Participant 5)

'I've had the confidence to ... explore. Let me do my own thing and then she [supervisor] is there to say, "Hey, that didn't work. This or that worked." But ... you grew in those situations where you were left alone.' (Student focus group, Participant 9)

'You do feel confident ... especially once you've had feedback on the prac, especially in 4 th year. It's quite nice to hear that you're doing what's expected of you, ... it helps if they give constructive feedback.' (Student focus group, Participant 1)

\section{Discussion}

The literature supports the findings that the students are mark driven and that they fear failure. This behaviour often results in the lack of persistence, as noted with the millennium generation, owing to their need to receive constant praise and being unfamiliar with receiving and/or coping with negative feedback. ${ }^{[8]}$ These students' unrealistic perceptions of themselves, continuous access to the internet and technology, and need for high marks, which is not always well correlated with their effort, were also noticed by their supervisors. As a result of these peculiar generational characteristics, several authors suggest that millennium students, although being more technologically savvy, have difficulty communicating in traditional formats. They therefore prefer group learning and peer work, where their interactions demonstrate their drive for high achievement. The students' strategic approaches to studying, linked especially to tasks involving high stakes, necessitate the need to link every learning activity to clear educational goals and outcomes that are directly relevant to their learning. ${ }^{[8]}$

The difficulty with clinical reasoning can partially be explained by the students' limited experience as novice therapists, who may lack the ability to integrate theory and practice. Completing a comprehensive assessment, and creating a prioritised problem list and contextualised client treatment regimen require clinical reasoning and clinical decision-making skills. The view that clinical reasoning skills develop over time is supported by the literature. Furthermore, clinical reasoning reportedly improves as students gain experience in the field, which allows them to acquire a repertoire of clinical practice skills to draw on. ${ }^{[9,10]}$ Students thus become more confident as they master the clinical decision-making process. ${ }^{[2,11]}$

Students' ability to engage with clinical reasoning is further hindered by a lack of understanding of the diverse contexts of their patients. A possible explanation for the restricted world view may be found in Amosun et al. $\mathrm{s}^{[12]}$ observation relating to the predominance of students from middle-class families in health science programmes. In SA this observation is supported 
in that these students enjoy greater access, as they are more likely to have studied at better-resourced secondary schools. Leibowitz et al. ${ }^{[13]}$ suggest that educators need to be aware of their own assumptions and should create safe spaces and opportunities for students to improve their cultural sensitivity and exposure to lifestyles that differ from their own lived experiences. Cultural sensitivity is vital for health professional education, given the diverse nature of the population for whom the graduates would be required to deliver a service. ${ }^{[14]}$ Buchanan and Cloete ${ }^{[4]}$ indicate that students need to be prepared for the experiences they will face during fieldwork to facilitate more effective planning for patient intervention. ${ }^{[15]}$ As supervisors, we need to ensure that students access psychological services for debriefing and counselling for emotional stress that placements could generate.

But how can supervisors and educators assist student learning? The findings suggest that clear guidelines and mentoring were found to be beneficial to learning. Students follow rule-based procedural reasoning to guide their actions when implementing an intervention. ${ }^{[10]}$ Sinclair's ${ }^{[10]}$ matrix for clinical reasoning and Schell and Schell ${ }^{[11]}$ suggest that students straddle the levels from novice to advanced beginner in clinical reasoning upon starting out as therapists. This study found that clinical supervisors can aid students' learning by verbalising the clinical reasoning processes when treating more complex cases. This practice helps to model more advanced clinical reasoning in context, which illustrates the relevance to the case being discussed.

Furthermore, feedback from students and supervisors suggests that reflexive practice and peer learning have been noted to start the process of building students' confidence with regard to their observational skills. These also enhance their ability to give feedback to their peers. This is supported by the literature, which shows that working with peers creates support, as students often experience the same tensions when trying to apply and transfer knowledge to new settings. ${ }^{[7]}$ In this way students are able to explore their professional reasoning and thoughts and evaluate their own interventions.

The findings from this study concur with the social constructivist learning experience in which students observe the supervisor providing intervention and improve their repertoire of practice skills though this modelled behaviour. ${ }^{[16]}$ The supervisor and student would then work on an intervention session together, thereby eliciting cognitive changes through guidance and prompting. Finally, students would try intervention sessions using prior knowledge and constructing new knowledge for their professional practice through integrating the observed learned experiences with their own experiences gained during fieldwork. ${ }^{[16]}$ This would help them to learn to use client-generated cues to guide intervention, the ability to anticipate and recognise client strengths and weaknesses based on the experience of other clients, and be flexible to alter and adapt their intervention plans. ${ }^{[10]}$ This feedback from the students and supervisors has shown that during fieldwork the latter are better able to facilitate graded learning experiences, which would create a store of professional reasoning and practice experiences for the student to use in future professional practice.

\section{Conclusion}

Fieldwork is a necessary and essential practical component of the OT undergraduate programme. This study provides insight into the difficulties that students experience when engaging in fieldwork. Students benefited from increased guidance and mentoring and the use of active teaching strategies, which allowed them to accept greater responsibility for their learning. Both academic and clinical supervisors play a vital role in modelling therapy, demonstrating clinical reasoning and providing structured learning experiences where students can be supported to master concepts and be empowered to practise independently. In the context of the current diverse student intake at tertiary institutions, it is necessary that we acknowledge our cultural identities and be reminded of students' inexperience in understanding the cultural contexts of their clients. It is therefore advisable for educational programmes to allow opportunities for supervised debriefing after fieldwork experiences for learners and practitioners to learn from one another.

\section{References}

1. Health Professions Council of South Africa (HPCSA). Professional Board for Occupational Therapy, Medical Orthotics and Prosthetics and Arts Therapy. The Minimum Standards for Training of Occupational Therapists. Form123B. HPCSA: Pretoria, 2009.

2. Gray M, Clark M, Penman M, et al. New graduate occupational therapists' feelings of preparedness for practice in Australia and Aotearoa/New Zealand. Aust Occup Ther J 2012;59(6):445-455.

Bille S, Choy S. Learing the Let S, Choy S. Learning through wok: Energing perpectives and new

4. Buchanan H, Cloete L. Preparing students for the complexities of practice learning. In: Lorenzo T, Duncan M, Buchanan H, Alsop A, eds. Practice and Service Learning in Occupational Therapy. New York: John Wiley, 2006:73-87. 5. Emslie B. Clinical occupational therapists' experience of their role as clinical educators during the fieldwork experience of occupational therapy students. MPhil. Cape Town: Stellenbosch University, 2012. http//:scholar. sun.ac.za/bitstream/handle/10019/Emslie_clinical_2012.pdf (accessed 9 October 2015).

6. Snyman MA. Assessment of professional behaviour in occupational therapy education: Investigating assessor understanding of constructs and expectations of levels of competence. MPhil. Cape Town: Stellenbosch University, 2012. http://scholar.sun.ac.za/handle/10019.1/20037 (accessed 9 October 2015).

7. Rutter L. 'Theory' and 'Practice' within HE professional courses - integration of academic knowledge and experientia knowledge. 6th LDHEN symposium, Bournemouth, UK, 2009. http://eprints.bournemouth.ac.uk/10130/2/LDHEN LR_paper.final.pdf (accessed 16 August 2014).

8. Hills C, Ryan S, Smith DR, Warren-Forward H. The impact of 'generation Y' occupational therapy students on practice education. Aust Occup Ther J 2012;59(2):156-163.

9. Carpenter C Suto Me Qulit Blackwell Publishing 2008 .

10. Sinclair K. Exploring the facets of clinical reasoning. In: Creek J Lawson-Porter A, eds. Contemporary Issues in Occupational Therapy: Reasoning and Reflection. 2nd ed. UK: Wiley and Sons, 2007:143-160.
Onclair K. Exploring the facets of clinical reasoning. In: Creek J Lawson-Porter A, eds. Conten

11. Schell BA, Schell J. Clinical and Professional Reasoning in Occupational Therapy. Philadelphia, USA: Lippincott Williams and Wilkins, 2008:1-433.

12. Amosun S, Hartman N, Janse van Rensburg V, Duncan E, Badenhorst E. Processes in widening access to undergraduate allied health sciences education in South Africa. Afr J Health Professions Educ 2012;4(1):34-39. http://dx.doi.org/10.7196/AJHPE.138]

13. Leibowitz B, Bozalek V, Carollissen R, Nicholls N, Rohleder P, Swartz L. Bringing the social into pedagogy: Unsafe learning in an uncertain world. Teaching in Higher Education 2010;15(2):123-133.

14. Frenk J, Chen L, Bhutta ZA, et al. Health professionals for a new century: Transforming education to strengthen health systems in an interdependent world. Lancet 2010;6 (9756):1923-1958. [http://dx.doi.org/10.1016/S01406736(10)61854-5]

15. Rodger S, Fitzgerald C, Davila W, Millar F, Allison H. What makes a quality occupational therapy practice placement? Students and practice educators' perspectives. Aust Occup Ther J 2011;58:195-202.

6. Schunk DH. Learning Theories: An Educational Perspective. 6th ed. Boston, USA: Pearson, 2012

Appendix A. Schedule of questions for student semistructured interviews

1. Describe your experiences of the OT programme during your training. (Probe: Negative or positive experiences?)

2. Do you think that clinical fieldwork placements are valuable and why? (Probe: Please give examples of positive experiences that contributed to your learning. Did you have any negative experiences?) (What do you feel makes a good supervisor?)

3. If you had an opportunity to change anything about fieldwork, what would you change?

4. How do you feel about assessing and treating clients in the various fields of OT? (Probe: What do you think helped or would have helped with this?)

5. Do you feel prepared for the planning of treatment programmes and sequencing of treatment sessions? What would assist with this?

6. Do you feel you are able to evaluate the outcome of your treatment intervention? What helped or would have helped you with this?

7. The purpose of this interview was to explore your perceptions and concerns related to the fieldwork experience. Is there anything you anticipated me asking that I did not? Please feel free to bring up any topic that might have been missed. 